\title{
Erratum to: Why so many deep brain stimulation targets in Tourette's syndrome? Toward a broadening of the definition of the syndrome
}

\author{
Mauro Porta $^{1} \cdot$ Christian Saleh $^{1} \cdot$ Edvin Zekaj $^{2} \cdot$ Carlotta Zanaboni Dina $^{1}$. \\ Alberto R. Bona ${ }^{2} \cdot$ Domenico Servello $^{2}$
}

Published online: 9 August 2016

(c) Springer-Verlag Wien 2016

Erratum to: J Neural Transm (2016)

123(7):785-790

DOI 10.1007/s00702-015-1494-1

In the original article, the authors' given names were inadvertently not published. The correct author line, with full names, should read as follows:

Mauro Porta, Christian Saleh, Edvin Zekaj, Carlotta Zanaboni Dina, Alberto R. Bona, Domenico Servello.

The online version of the original article can be found under doi:10.1007/s00702-015-1494-1.

Mauro Porta

mauroportamilano@gmail.com

Christian Saleh

chs12us75010@yahoo.com

1 Tourette Center, Galeazzi Clinical and Research Hospital Center, Milan, Italy

2 Functional Neurosurgery, Galeazzi Clinical and Research Hospital Center, Milan, Italy 